\title{
7. Persuasive Strategies for Advergames
}

\begin{abstract}
Due to the interactive nature of digital games, the factors that determine the conceptualization of advertising strategies for advergames are related not only to the way the advertising message should be conveyed but also to how the game motivates players to play it and how it engages them to keep playing. In this chapter I present and discuss six factors that determine the conceptualization of persuasive strategies for advergames. These six factors are: advergames' objectives, integration of products in advergames, advergames' target audience, advergames' visibility, advergames' credibility and advergames' playability.
\end{abstract}

Keywords: persuasive strategies, advergames, persuasive communication, digital advertising, conceptual model

In the previous chapter I presented a theoretical model to explain how persuasiveness can be implemented within digital games. This theoretical model can be used for the study and implementation of persuasive strategies within advergames. However, if we want to apply the theoretical model to the study of an advergame, it is important to first recognize which factors have determined the advertising strategy. Once we understand what those factors are, we can evaluate, making use of the theoretical model, whether the strategy has been effectively implemented within the digital game. Furthermore, we can also evaluate if the advertising strategy does fit with the medium selected to convey the advertising message, in this case a digital game. I have thus identified six factors that should influence advertisers' decisions: advergames' objectives, products in advergames' integration, advergames' target, advergames' visibility, advergames' credibility and advergames' playability. In the following sections I explain how these factors influence advergames' process of decision-making.

De la Hera, Teresa, Digital Gaming and the Advertising Landscape. Amsterdam: Amsterdam University Press, 2019. DOI 10.5117/9789462987159_CHO7 


\section{Advergames' Objectives}

Among the factors that should be considered when conceptualizing advertising strategies for advergames are the objectives of the strategy. When I say the objectives of the strategy, I mean not only the advertising objectives but also the game objectives. Advergames are a form of advertising that because of its interactive nature requires input from active players, who voluntarily approach the game and play it. Therefore, the objectives of an advertising strategy for an advergame should take into consideration not only how to convey the advertising message but also how to motivate players to play the game and how to engage them to keep playing. I will later discuss in depth other elements that motivate players to play the game and keep playing, but in this section I am going to focus on how the objectives of the game and their relationship with the advertising objectives have an important role in that process.

The game and digital communication scholars Heide and Nørholm (2009) have identified three possible relationships that can be established between the advertising objectives and the objectives of a game: (1) the game goal and the advertising goal overlap; (2) the game goal and the advertising goal are detached from each other; and (3) the game goal and the advertising goal are somehow related but do not completely overlap. In advergames in which the game goal and the advertising goal overlap, in order to be successful in the game players need to demonstrate that they understand the advertising message (2009, p. 59). As I have previously argued, although in educational games, for instance, a complete overlap between the game goal and the learning goal makes sense because it is necessary that after playing the game players have learned the lesson taught within the game, in advergames this overlap is not necessary and in some cases it is even not recommended. One of the central characteristics of advertising communication is that it is typically unwanted communication (Messaris, 1997, p. 5). Therefore, in order to avoid players' resistance the persuasive intentions of advergames should not be obvious.

The overlap between the game goal and the advertising goal can be useful in advergames that want to focus on products benefits, especially when it is possible for the player to interact with a product to understand its benefits. In the case of Hit it Pure (Hello Design, 2009) — previously discussed on p.35, if players understand the capabilities of the Callaway Golf drivers, they can perform better in the game. At the same time, they come to appreciate the benefits of the drivers, which is the advertising goal of the game.

However, in advergames whose purpose is to change players' attitudes or behaviors, the overlap between the advertising goal and the game goal 


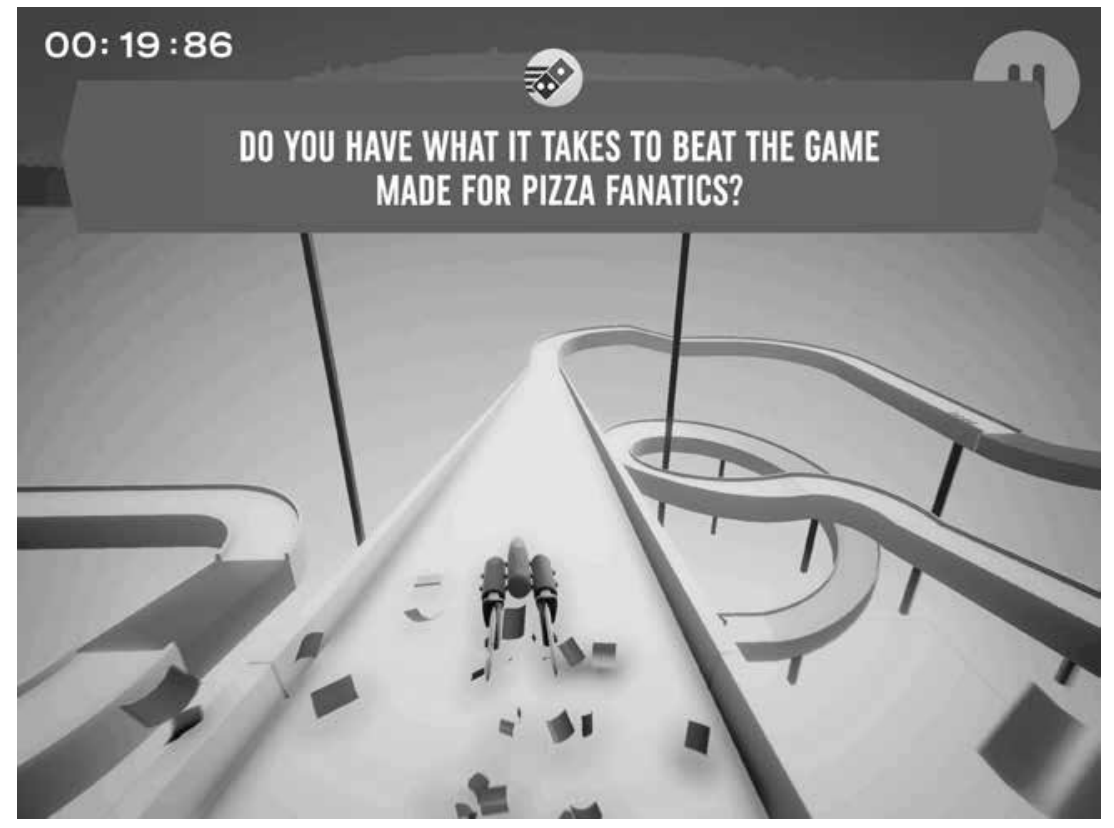

Figure 14. Domino's Piece of the Pie Pursuit (CP+B and Templar Games, 2018).

does not work in the same way because players can act as if they agree with the point of the game in order to win it without actually changing their beliefs or actions in the physical world. For that kind of games, an alternative relationship between the game goal and the advertising goal could fit better with the objectives of the creative strategy.

Another option is to design an advergame in which the game goal and the advertising goal are detached from each other. This option can be useful when there is no specific information that needs to be understood by the player. An example of this is the advergame Domino's Piece of the Pie Pursuit (CP+B and Templar Games, 2018). This is a six levels physics-based game in which the player should guide a pizza cutter shaped car along a boost-filled track (see Figure 14). In this case, the game has nothing to do with eating pizza, and does not teach us anything about the quality of the pizza, how it is made, the ingredients or any other characteristic of the product. The game mechanics have nothing to do with the product itself or any message related to the brand's identity. But winning the game can mean winning a free Domino's pizza. Therefore, the advergame was able to create brand's awareness, even when the advertising goal and the game goal were completely detached from each other. 


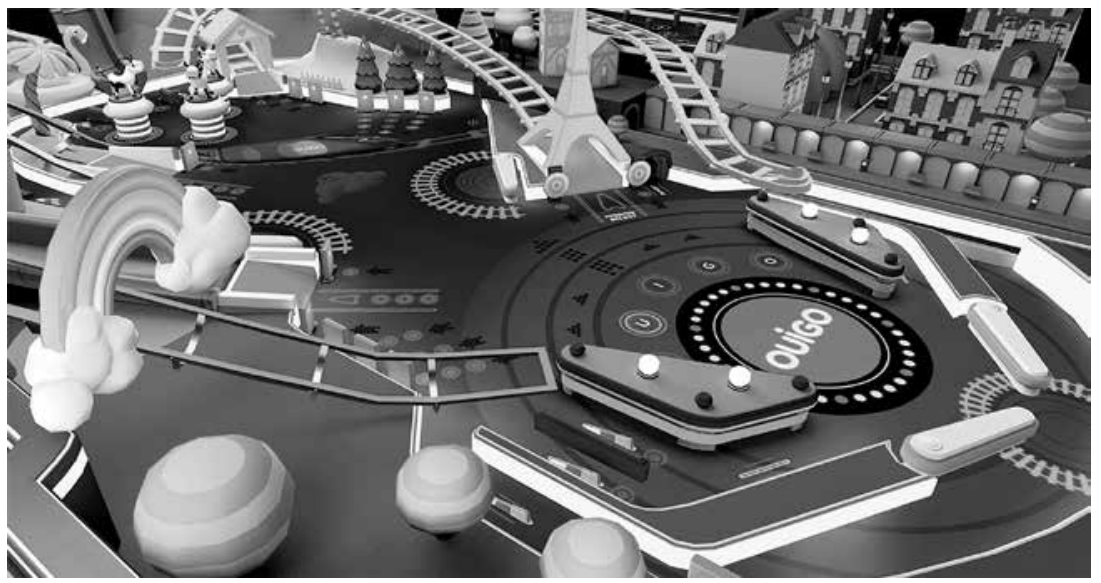

Figure 15. OUIGO - Let's Play (ROSAPARK \& MerciMichel, 2017).

The final option is to design an advergame in which the game goal and the advertising goal are somehow related to each other although they do not overlap. An example of this is the advergame OUIGO - Let's Play (ROSAPARK \& MerciMichel, 2017), designed to promote the low-cost and high-speed French train branch of the SNCF. The advertising goal of this game is to convey the message that this train is cheap and fast. On the other hand, the game goal of this pinball, as all pinballs, is to collect as many points as possible by striking different targets on the playfield. In this case, the advertising goal and the game goal do not overlap but at the same time are strongly related because the storyline of the game presents a narrative fiction in which the train acquires an important role through the visual representation (see Figure 15) and the comparison established between the train ride and the values associated to pinball games (cheap and fast).

This fictional hyperbolic treatment of the product advertised establishes a balance between the symbolic and denotative representations of milk within the game. This makes that players take in the real information about milk provided within the advergame as part of the narrative fiction and not as a claim about the product, which in turn makes them to let their guard down against the persuasive message. Therefore, although the game goal and the advertising goal do not overlap, they are strongly related because they have in common a protagonist element, which is the product advertised within the game, the milk. This technique allows the advergame to convey the advertising message without using an overly obvious strategy. 


\section{Integration of Products in Advergames}

One of the factors to consider when conceptualizing a creative strategy for an advergame is how to integrate advertised products. The marketing scholar Scott J. Armstrong (2010) has identified five conditions that represent important aspects of the product that are determinant in choosing how products are presented to customers: the benefits, the involvement of the customer with the product, the types of needs the products cover, whether it is a commercial or a pro-social product and whether the customer can evaluate the features of a product before buying it.

To illustrate how these features can influence the advertising strategy of an advergame I will analyze how the product has been integrated in the game $F M X$ (Valentin \& Byhr et al., 2010). The advergame commissioned by Volvo aims to present a new truck model for the construction sector by displaying its benefits in comparison to other trucks. For that purpose, the simulative driving-test experience serves to illustrate how the new model can be useful in difficult situations that drivers confront in the physical world, such as climbing a steep hill. In the case of the steep hill the game shows the player how to use the i-Shift control to let the truck handle the downshift.

Making a decision about buying a truck is a high-involvement situation. In high-involvement situations consumers are more worried about the claims of the advergame than in low-involvement situations, in which they pay little attention (Armstrong, 2010, p. 21). If a player is thinking about buying a truck, which model to buy represents an important decision because the investment is high. Choosing the right model can have consequences for profits, for instance. Therefore, a player who might be interested in buying the new model Volvo truck is probably going to pay special attention to the claims of the advergame.

In the example we are analyzing here, a Volvo truck is a utilitarian product purchased for work needs. Utilitarian products are used to solve problems or to cover basic needs while hedonic products are primarily purchased for enjoyment (Armstrong, 2010, p. 22). In this case it is logical to think that the customer wants to have all the information possible about the truck before making the decision to buy it.

Furthermore, in this case of the Volvo truck we are faced with a product whose features can be evaluated only after purchase. Only when customers buy the truck and start working with it will they become conscious of the problems it may have or of the benefits it offers in comparison to other trucks they have driven before. Therefore, giving players an 


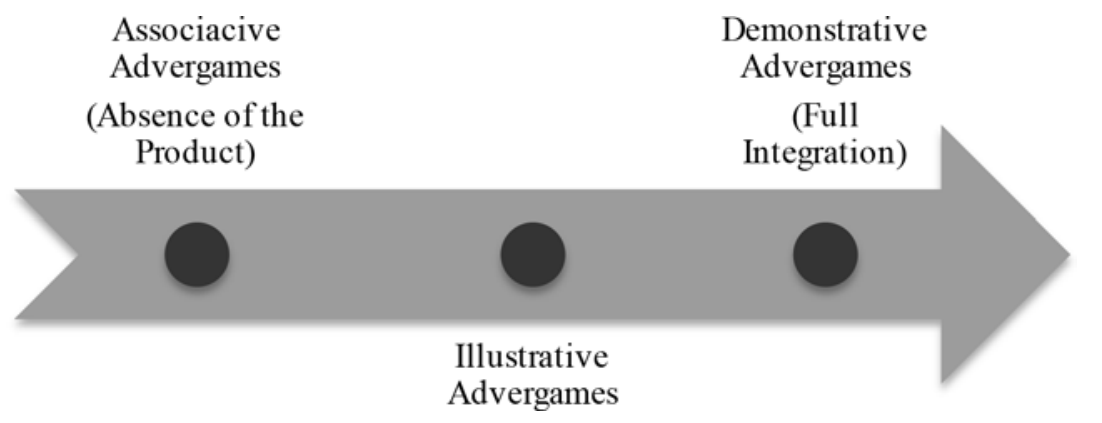

Figure 16. Integration of the Product within the Advergame. Source: Author's Design.

opportunity to have a virtual driving experience of the truck might help them to appreciate features that otherwise would not be visible until after purchase. This experience may help them to make their decision feeling that they have more complete information about the truck they are buying.

It follows that the aforementioned characteristics should guide the decision of how to represent the product within the advergame and how the player is going to be able to interact with it. In their research report on advergames, Chen and Ringel (2001, pp. 3-4) identified three levels of product-game integration: associative, illustrative and demonstrative. Associative advergames correspond to those in which the product advertised is not present at all and therefore present the lowest level of product-game integration. At the other extreme, demonstrative advergames correspond to those that are simulations of products or services and therefore present the highest level of product-game integration. Between the two extremes, illustrative advergames are those that present the product but are not a simulation of it. Therefore, the level of integration of the product in this case lies between the two mentioned extremes. However, I see these three levels of product-game integration not as isolated steps but as part of a continuum along which is possible to situate advergames (see Figure 16).

Associative product-game integration occurs when advergames support brand awareness through lifestyle association. Associative integration focuses the advertising message on intangible properties of the products, services or brands advertised, appealing to the feelings or emotions associated with them. It follows that the persuasive dimensions associated with the third level of persuasion are useful for the design of associative advergames. An example of associative integration is Scorpio (CLM BBDO \& Les 84,2010 ), an advergame released to advertise a brand of French perfumes. The game is a suggestive experience through three skill games starring a 


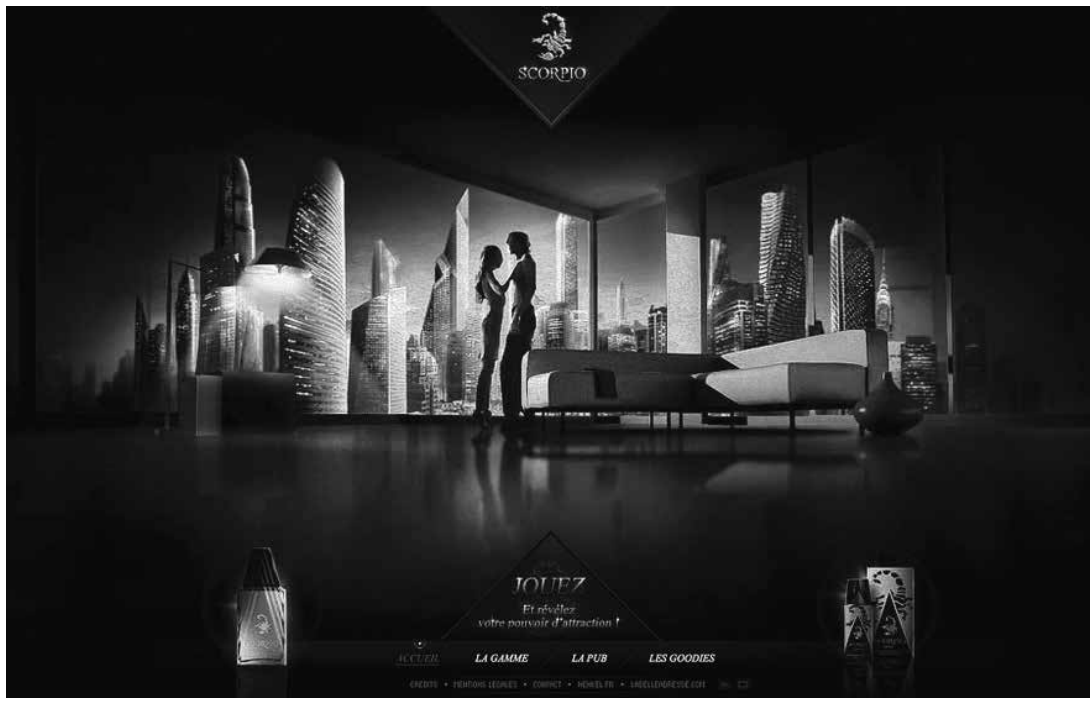

Figure 17. Scorpio (CLM BBDO \& Les 84, 2010).

sensual couple. The associative advergame aims to link the brand with the power of sensual attraction, implying that those who use the perfume will become irresistible to the opposite sex (see Figure 17).

Illustrative product-game integration prominently features the product itself in game play. In illustrative advertisements, products or services are contextualized by focusing more on social and cultural context while their features are deemphasized. An example is the fighting theme advergame Battle of Cheetos (Goodbye Silverstain \& Partners \& North Kingdom, 2010). In the game the player has to create an army of Cheetos soldiers and fight for the control of different sites across the web. Sites like Gizmodo, BoingBoing, Mashable, Digg or Kotaku are the battlegrounds. In this illustrative advergame, Cheetos products come to life to become the main characters of the game (see Figure 18). In this case we are dealing with a low-involvement product; therefore players are not going to be interested in the benefits of the product and are not going to pay attention to the advertising claims. However, the advertisers intended to associate the product with a fun experience. For this reason, the product is integrated into the game not in its natural context but in a funny context that triggers in players the association intended.

Demonstrative product-game integration refers to those advergames that "boost messaging effectiveness by presenting the product in its natural context and inviting the consumer to interact with it" (Chen \& Ringel, 


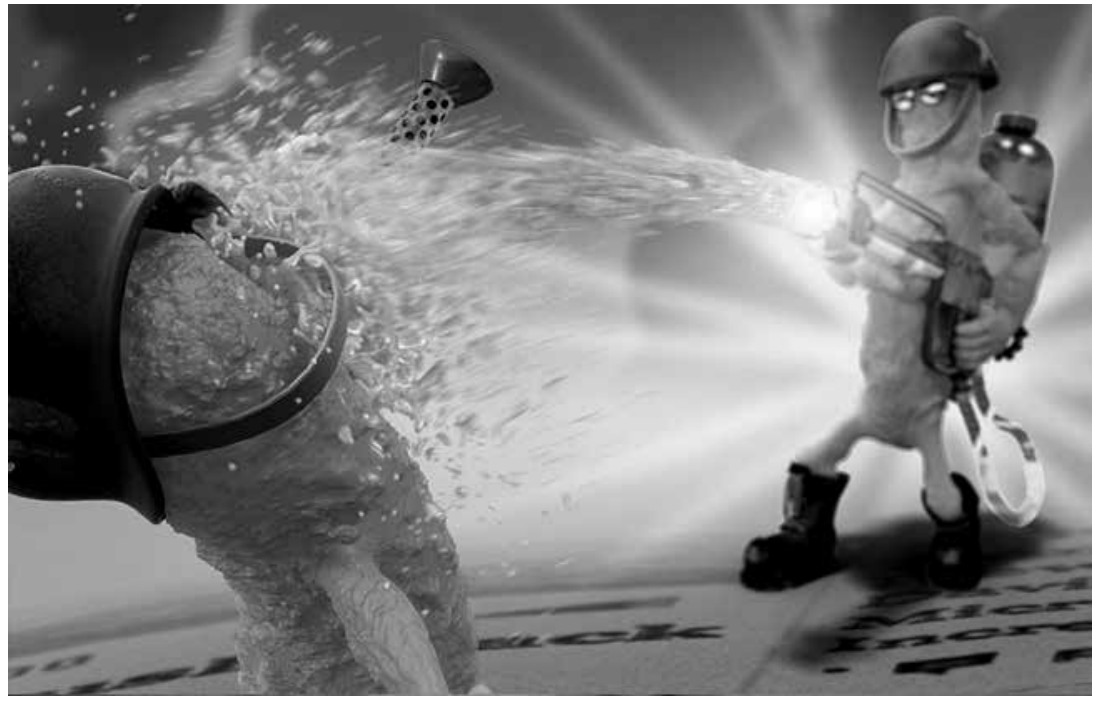

Figure 18. Battle of Cheetos (Goodbye Silverstain \& Partners \& North Kingdom, 2010).

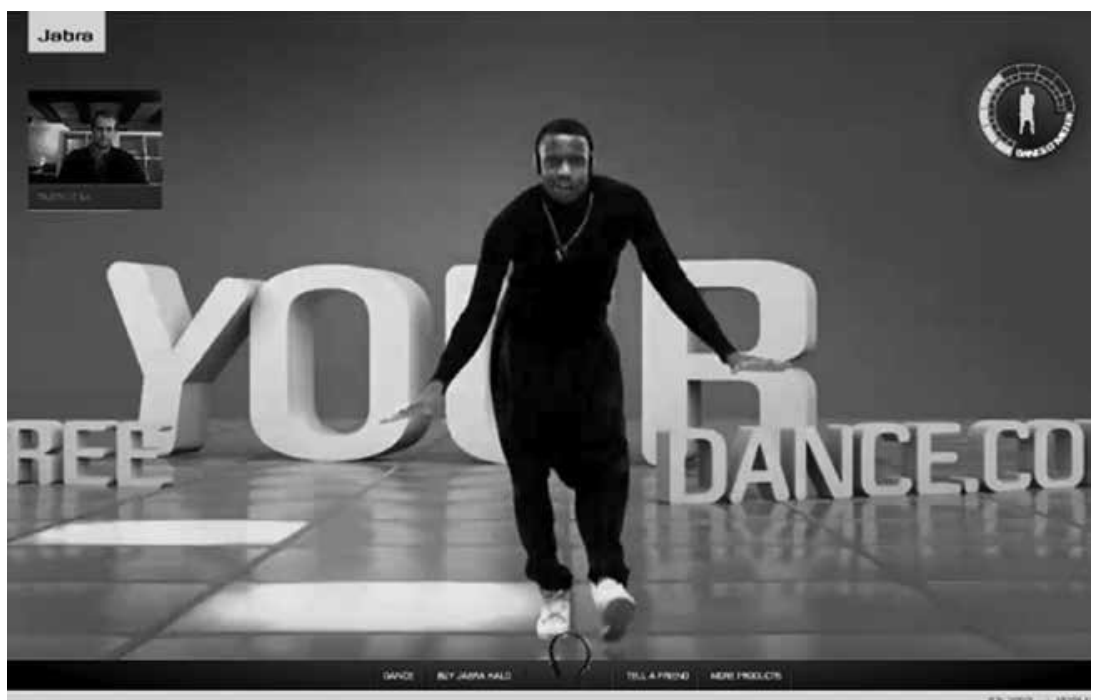

Figure 19. The dancer of Free your dance (Zupa et al., 2010) wearing the Halo headphones while dancing.

2001, p. 4). Demonstrative advertising provides direct information about the nature of a product. This strategy advertises the products' benefits. Demonstrative integration can be seen in Free your dance (Zupa et al., 2010) a game released to advertise Jabra Halo wireless headphones. The 
game challenges users to a dance competition via webcam wearing wired headphones against a dancer wearing Halos (see Figure 19). Based on the performance, users are given a score, one that is never quite as good as it could be using wireless headphones, providing evidence of the feeling of freedom acquired by wearing wireless headphones.

\section{Advergames' Target}

The target of the advergame is another of the factors that can influence the advertising strategy. I have identified three strands of advergames' target that are important in the process of conceptualization of advertising strategies: (1) their demographic, psychographic, and geographic characteristics; (2) their attitude toward the game; and (3) their attitude toward the advertising message.

The definition of the target in terms of demographic, psychographic, and geographic characteristics is the first strand of advergames' target that should be taken into consideration when designing the creative strategy. The advertising communication scholar Henri Joannis notes that it is important to know about the gender, the age, the education, the location, the spending habits, the product needs and some lifestyle indicators of the target players (1996, p. 19) to define an advertising strategy.

Returning to one of the advergames that have been already mentioned, in the case of Get the Glass! the target of the game posed a challenge for its designers. The game was aimed at increasing milk consumption among U.S. citizens in general. That means that advergames designers did not have specific psychographic or geographic characteristics to define the game experience. In order to overcome this problem, the designers made two intelligent decisions. The first one was to choose a whole family, the Adachi family, instead of a unique character, to star in the game. The family was composed of four members: a mother, a father, a son and a daughter (see Figure 20). This decision helped to make large segments of the U.S. population feel identified with the game. Secondly, in order to overcome possible problems related to different players' skills, the designers opted for an interface design that simulated a board game (see Figure 21). This type of interface design made it easy for most of the U.S. population to understand how to play the game. Therefore, in this case, taking into consideration the target definition helped to make decisions that would engage a larger group of players. 


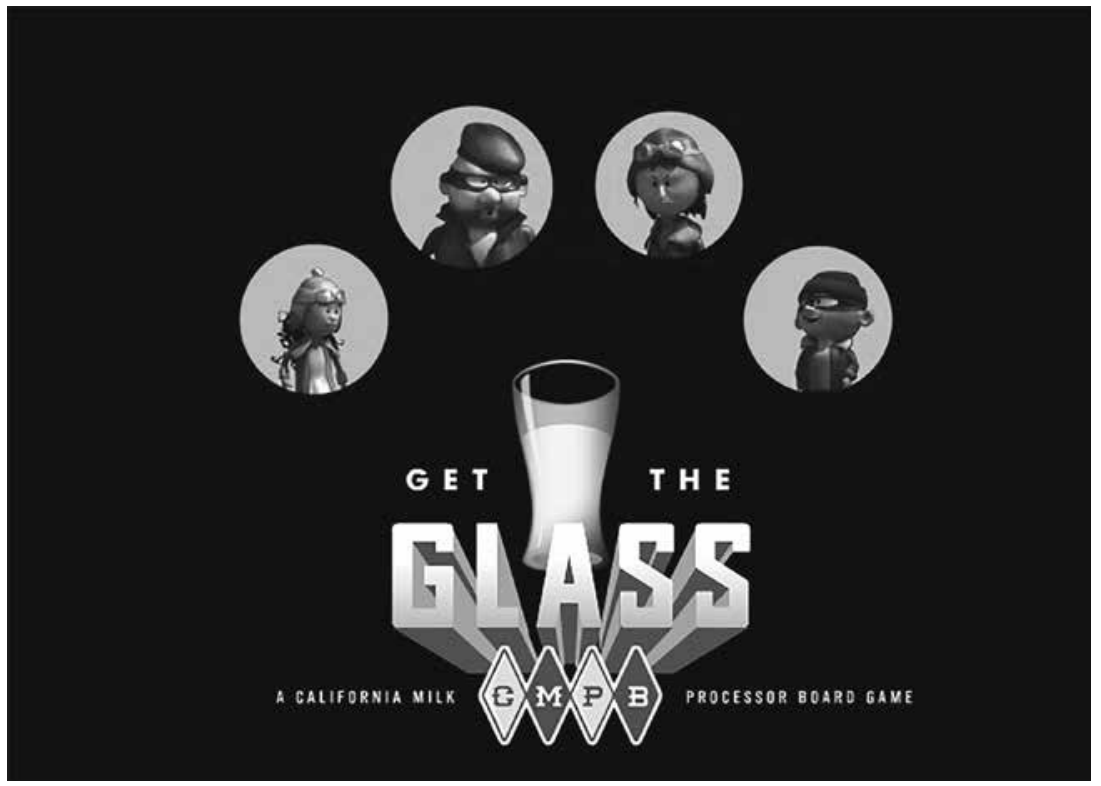

Figure 20. Adachi Family.

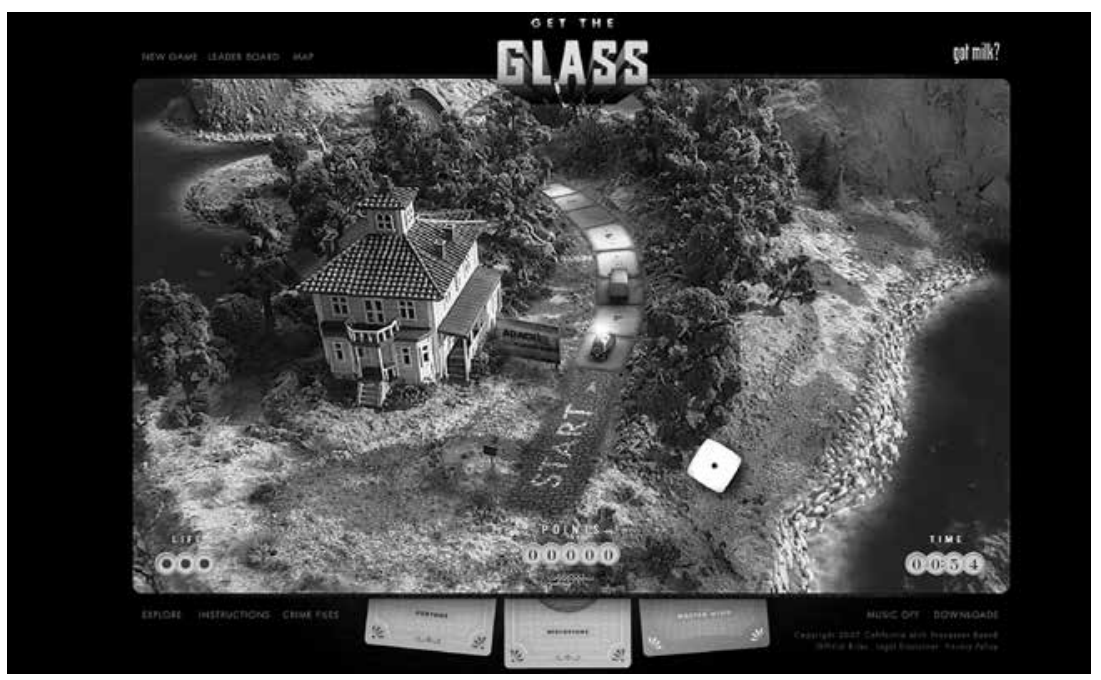

Figure 21. Get the Glass! simulates a board game.

In order to make decisions related to the target of the advergame, it is also important to anticipate players' attitude toward the advertising message. As I have previously stated, one of the central characteristics of advertising communication is that it is typically unwanted communication (Messaris, 
1997, p. 5). Therefore, players' resistance to persuasive communication is one of the factors that should be taken into consideration when designing an advergame's creative strategy.

According to the communication scholar Paul Messaris, consumers are often armed with 'shields' that usually consist of firm beliefs, rival loyalties or established preferences that they may raise to protect themselves against persuasive communication. The author explains that protective shields can be external or internal. External shields are related to people's social attachments to culture, their reference groups, their social class and their emotionally grounded experiences. On the other hand, internal shields are related to people's overall perspective or view of the world, their values, their emotions and their expectations about themselves and their social world. It follows that these 'shields' with which players can confront persuasive communication can affect advergames' effectiveness. Therefore, one of the tasks of advergames' designers is to avoid players' resistance to persuasive communication. In order to address the problem of players' resistance, Messaris states that advertisers can work on advertisements' visibility and credibility (1997, p. 3). In the case of advergames, I state that player's resistance can also be addressed by advergames' playability. In the following sections, I describe in depth how these three features should be considered in the conceptualization of advergames' advertising strategies.

Furthermore, due to their interactive nature, advergames need to entice players to adopt an active stance that differs from the passive attitude of traditional media audiences. Therefore, it is important to retrieve information about their attitude toward digital games in general as well as about their preferences and skills. This will help advergames' designers choose an attractive game concept that encourages the target to play and engages them to keep playing. However, advertisers need to know not only about players' skills or their manifested preferences but also what arouses in them certain feelings or emotions that can create an immediate link between players and brands.

\section{Advergames' Visibility}

The goal of advergames' visibility is to make players aware of the existence of the advergame, which is the first step in making players want to play it. Advergames' visibility depends on where the advergame is placed and when it is available to be played. As discussed in detail in chapter 3 , the evolution of technologies has enabled the proliferation of different types of advergames 
that can be played on multiple platforms, such as mobile advergames, online advergames or console advergames and which are also placed in many different contexts, such as game portals, app stores, microsites or banners.

The decisions taken on the form and placement of the advergame have undoubtedly consequences on advergames' visibility, i.e. on players' awareness of its existence. Decisions on visibility may also affect advergame's effectiveness. To illustrate this, let us compare three Volkswagen advergames from 2009 with different forms and placements: Volkswagen Polo Challenge (Fishlabs, 2009) a racing game for the iPhone and iPod Touch, Golf GTI Tracks (KMF, Artificialduck Studios, Electric Umbrella, \& FxLab, 2009) a racing game placed on a microsite online, and Volkswagen: The New Golf (Tribal DDB, 2009) a banner puzzle game placed on high-traffic websites.

We can assume that previous beliefs, loyalties or established preferences of players toward Volkswagen's models before playing the game were similar because the three advergames were released in the same year. However, according to the multimedia communication scholar Christina Spurgeon, there are other factors that may have affected players' resistance to advertising communication (2008, p. 29). From the three advergames analyzed here, the Volkswagen: The New Golf, placed on banners of high-traffic websites, was presumably the most visible. However, according to Spurgeon, this advertising technique experiences high levels of end-users' resistance to advertising communication (Spurgeon, 2008, p. 29). On the other hand, whereas Volkswagen Polo Challenge, the advergame released for the iPhone and iPod Touch, was visible to fewer players, it could avoid players' resistance to intrusive advertising because players who downloaded the advergame from the App Store did it voluntarily.

Furthermore, the game placed on the banner had to compete against other contents present on the site for players' attention, whereas in the cases of the microsite or the iPhone game, advertisers had total control of the context that surrounded the advergame. Consequently, the latter two did not need to compete against other content on the screen for players' attention. Therefore, those players who found and played these two advergames would probably have a more positive attitude toward their content. Nevertheless, this is not something that can be generalized because the factors that affect visibility vary from case to case. The point is that, when considering where to place the advergame, one needs to evaluate how visible it is going to be for players and the potentialities and the limitations of the placement selected.

When advertisers opt for placements that are less visible to players, in some cases an advergame's visibility needs to be reinforced by a complementary advertising action taken to make customers aware of its existence. 
These actions can range from viral advertising actions ${ }^{1}$ to big advertising campaigns including TV commercials, for instance. This is a strategy that can be effective when the advergame aims to convey a complex message that provides an amount of information impossible to be communicated by other forms of advertising or which enables an experience that becomes significantly meaningful for customers, bringing an evident benefit to the brand. Therefore, when the placement chosen for the advergame requires an extra effort to provide visibility to it, it is necessary to consider whether the benefit provided by the advergame is worth the investment.

The advergame Get the Glass! can be used again to illustrate this problem. This game is part of the bigger advertising campaign Got Milk?, with which the California Milk Processor Board aims to increase milk consumption among U.S. citizens. In this case, the advertisers created a narrative fiction around a family affected by physical and psychological problems due to the lack of milk consumption. This advertising campaign started with a series of TV commercials that presented the history of the family and encouraged viewers to help the members get a big glass of milk guarded in a fort, the Fort Fridge. In order to help the family, customers need to play an advergame placed online on a microsite specially created for it in which they have to accomplish a series of challenges.

In this case, the TV commercials helped to give visibility to the advergame. Furthermore, due to the complexity of the message conveyed through the advergame in this case the strategy was worthwhile. Evidence of the repercussion of this advergame is that it has had more than six million players to date.

\section{Advergames' Credibility}

The marketing scholars Scott B. MacKenzie and Richard J. Lutz define advertisement's credibility as the extent to which the target perceives claims made about the product or brand within it to be truthful and believable (1989, p. 51). An advertisement's credibility can help avoid players' disagreement with the advertising message conveyed (Messaris, 1997, p. 8). Furthermore, the persuasive communication scholar Daniel J. O'Keefe states

\footnotetext{
$1 \quad$ "Viral marketing describes any strategy that encourages individuals to pass on a marketing message to others, creating the potential for experiential growth in the message's exposure and influence. Like viruses, such strategies take advantage of rapid multiplication to explode the message to thousands, to millions" (Kirby \& Marsden, 2006, p. 8).
} 
that credibility is especially important when an advertisement calls for a substantial change in consumers' behavior (1990, p. 194).

According to MacKenzie and Lutz, the credibility of the claims made within an advertisement is a multidimensional construct that depends (1) on the targets' current perception of the truthfulness or honesty of the brand, (2) on advertising credibility, namely target's perceptions of the truthfulness and believability of advertising in general and (3) on the doubts the target can have about the advertisement's claims (MacKenzie \& Lutz, 1989, p. 51).

The perceived truthfulness or honesty players already have about the brand is something that advertisers have to deal with when designing advertising strategies for advergames. Depending on the brand's reputation, the objectives of the advergame can be completely different, and therefore, the strategy to follow will also change.

The persuasive communication scholars James B.Stiff and Paul A. Mongeau identified three dimensions on which advertising strategies can focus depending on the perceived truthfulness: the process of response shaping, the process of response reinforcing or the process of response changing (2003, pp. 5-9). Taking into consideration Stiff and Mongeau's (2003) claims, response-shaping advergames will be designed to introduce new brands or products to players. In this case advergames' designers cannot count on previous familiarity or loyalty; therefore, redundancy can help with recall and familiarity. An example of a response-shaping advergame is $F M X$ (Valentin \& Byhr et al., 2010), launched to introduce a new truck model for the construction sector from Volvo (discussed on p. 27). Because it is a new product, the advergame is focused not only on presenting its benefits in comparison with competitors' models, but also on presenting the new model visually, to increase familiarity with the product.

Response-reinforcing advergames are used to increase customer loyalty. In these cases, advertisers can count on players' previous confidence in the brand or the product advertised, and the objective will be to maintain and even increase that loyalty (Stiff \& Mongeau, 2003, p. 7). An example of a response-reinforcing advergame is Asylum 626. The familiarity and fidelity of players with the brand, Doritos, makes it not necessary to make the product continuously present within the game or to focus on its benefits, and in this case the advergame was focused on delivering a memorable experience.

In addition, response-shaping advergames have the objective of changing players' responses from one position to another (Stiff \& Mongeau, 2003, p. 9). An example of a response-shaping advergame is Get the Glass!. As previously discussed, the objective of this advergame was to increase milk consumption among U.S. citizens. The Milk Processor Board of California 
wanted to change players' attitudes and make them choose milk over other drinks. In order to achieve that purpose, the advergame's designers used strong arguments claiming milk's physical and psychological benefits, which were embedded within the game by making use of a fictional narrative.

The previous information and perceived truthfulness players already have about the brand and the perceptions of the truthfulness and believability they have regarding advertising in general can influence the doubts players can have about advergames' claims. In this sense, advergames have another attribute that can help overcome players' resistance related to credibility. The procedural and interactive nature of advergames allows them to deliver meaningful experiences, instead of just promising them. Therefore, this capacity of advergames can allow them to overcome players' doubts about a product's claims. For instance, in Hit it Pure (Hello Design, 2009) (discussed on p.35), the realistic physical settings of the game give the player the opportunity to experience what happens when a golf ball is hit with the FT-iQ and FT-9 drivers in the physical world, which makes it more difficult for the player to refute the claims made about the golf drivers than had they been made through explanatory texts, for instance.

\section{Advergames' Playability}

Due to their interactive nature, advergames need to entice players to adopt an active stance toward them that differs from the passive attitude of traditional media audiences. Whereas the majority of advertising forms are interruptive, advergames are usually defined as a marketing strategy that operates on pull, which means that it is the player who voluntarily approaches them and interacts with the advertising message (Kempt, 2009, p. 25).

However, simply because an advertising message has the form of a digital game does not mean that it is going to automatically attract consumers to play it. Rather, advergames need to be appealing enough to encourage players to start playing them and engage players sufficiently to keep them playing in order to expose them to the games' persuasive messages. Furthermore, it is also important to recognize what can make players stop playing games.

What makes players start playing, keep playing or quit playing advergames is related to all the experiences they feel when interacting with the game system. The term playability has been defined to identify and analyze all the attributes of digital games that contribute to this process. The software engineers González Sánchez, Gutiérrez Vela, Montero Simarro and 
Padilla-Zea state that the term playability is related to the degree to which a game is fun to play and is usable, with an emphasis on the interaction style and plot-quality of the game (2012, p. 1034). Advergames' playability can be measured by the "degree to which specific users can achieve specific goals with effectiveness, efficiency and, especially, satisfaction and fun in a playable context of use" (2012, p. 1037). González Sánchez et al. identified the attributes of digital games that influence playability as: motivation, learnability, memorability, efficiency, utility and satisfaction. In what follows I analyze how these six attributes can influence advergames' persuasive intentions and therefore should be taken into consideration when designing an advertising strategy for such games.

\section{Motivation}

Motivation is the capacity of digital games to encourage players to undertake specific actions and continue undertaking them until they are completed (González Sánchez et al., 2012, p. 1040). Motivation has an important role in making players want to play the game but also in giving them the resources they need to persevere in overcoming new challenges. Motivation is important not only to make players play the game but also to influence their attitude toward the advergame. Players' attitude toward the advergame can influence advergames' credibility, making it easier or more difficult to overcome players' resistance to persuasive communication. Therefore, motivation is an important element to consider in the design of advergames' advertising strategy.

Motivation can be generated in advergames by encouragement, appealing to curiosity or self-improvement, and providing diversity. The degree of player encouragement is affected by the level of confidence felt by players when facing new game challenges (González Sánchez et al., 2012, p. 1040). This is directly related to the learnability and effectiveness of the game, which are described below.

An advergame that does a great job in terms of motivation is World's Worst War (discussed on p. 9o). In order to play the game, players needed to buy one of the bags of Tohato snacks in which they found an access code to join one of the two online armies with which they could fight a battle every day at 4 a.m. The fact that they needed to get the access code and the condition to play at night generated an initial curiosity about the game before playing it. Once in the game, players were invited to join one of the two armies and choose their battlefield from thirty-one spots. Moreover, they were encouraged to gain promotion in the army by recruiting friends as warriors under them. The ambition to improve and perform better in the game than their friends 
and acquaintances motivated them to keep playing (Billich, 2010, p. para 5). Players also had the opportunity to think up and implement strategies with the objective of beating their enemies. The diversity of possible strategies that could be implemented was also a motivation for players, who started to meet up on social networks to set up strategies (Billich, 2010, p. para 7).

\section{Learnability}

Learnability is related to players' capacity to understand what they have to do in the game and understand how to do it. An advergame's learning curve must be carefully designed to avoid players' stagnation, and the design of this learning curve may be affected by the nature of the game. Stagnation occurs when "players are playing a game and reach a point where they appear to be stuck, with no way to go on" (Rollings \& Adams, 2003, p. 271). While some games put the player on a steep learning curve during the first phases, others games propose a step-by-step learning curve that guides the player for some time. In order to avoid problems related to learnability some advergames' designers opt for game designs that are variations of very popular games, such in the case of Flip the Mix (KwelBox, 2002) an M\&M's variation of the popular Bejeweled (Popcap Games, 2001). The problem of following this strategy is that it may result in a lack of curiosity and encouragement, thus reducing motivation.

Another advergame which has problems related to learnability is Scorpio (discussed on p. 154). The advergame consists of three mini-skill-games. The problem comes when the player realizes that there is little explanation or indication about what to do in each of the challenges. Two of them are intuitive, and it is easy to understand what to do even without any explanations. But one of them is not intuitive at all, and moreover, it gives the player a very limited amount of time to understand how to play the game. If the player does not get what to do within a few seconds, the game finishes and the player needs to play it again. This set-up causes frustration in players who can abandon the game, and it risks linking this frustration feeling to the brand.

There are many solutions to help the player in the process of learning how to play the game, but the important thing to take into account is that the learning curve should be adapted to the skills and expectations of players. A poorly designed learning curve may cause frustration and players' stagnation. Moreover, if the game goals and the advertising goals overlap, a poorly designed learning curve can cause misunderstanding of the advertising message. 


\section{Memorability}

Learnability is directly related to memorability, which according to Rogers et al. measures how easy it is for players to remember how to play the game once they have learned how to do it (Rogers et al., 2011, p. 21). This is especially important if advertisers expect players to play the advergame more than once, which can be useful in increasing familiarity and recall. Nevertheless, designing an advergame that is easy to learn and easy to remember how to play can in turn create problems in terms of motivation. An example of this is the advergame Nespresso Variations (Soleil Noir \& Chez Eddy 2010) released to introduce some new flavored coffee capsules for the coffee machine Nespresso. In the game the player has the opportunity to play three different mini-games, each one corresponding to one of the new varieties of coffee. The problem is that the games are very simple to play and do not challenge the skills of the player. This can result in a disappointed player, and, again, this feeling may be linked to the product or the brand advertised.

Therefore, inasmuch as most advergames are designed to be casual games, a good strategy to follow to avoid this problem is to design advergames that are "easy to learn, but difficult to master" (Juul, 2010, p. 41). This means that even when the learning process is quick and easy to remember the game should demand that players continually expand their skills in order to progress. This will help to maintain players' motivation during the game session.

\section{Efficiency}

Efficiency is related to the way the game supports players in achieving objectives and reaching the final goal (Rogers et al., 2011, p. 21). A good balance between the objectives to be achieved and the challenges to overcome is important to keep players engaged in the game (González Sánchez et al., 2012, p. 1039). Therefore, the structure of the advergame has an important role in its efficiency. This is something that has to be taken into consideration when designing advergames' advertising strategies because it has been demonstrated that when consumers have problems trying to organize complex advertising structures, they retain very little information (Plummer, 1971, p. 322).

Furthermore, advergames' efficiency is directly connected with the concept of meaningful play defined by Salen and Zimmerman to refer to the creation of meaningful game experiences for players (2004, p. 6o). Meaningful play occurs when the relationship between actions and outcomes 
in a game are both discernable and integrated into the larger context of the game. By discernable the authors mean that the player should be able to perceive the result of the game action, and by integrated they refer to the fact that an action performed by a player should affect the whole play experience rather than have only an immediate significance (2004, p. 34-35). Therefore, the creation of meaningful experiences is important for the efficiency of the advergame, which is also related to the effectiveness of the advertising message because supporting players to reach the final goal of the advergame is a way to ensure that they experience the complete branded experience.

An example of an advergame with efficiency problems is Capri-Sonne Fun World (Netzbewegung GmbH, 2009) launched to advertise the juice concentrate drink sold in silver pouches Capri-Sonne (Capri Sun). The game presents a playful world that the player can explore by making use of a hang-glider to discover mini-games and activities. The problem is that although there are several challenges the player can face, there seems to be no final goal at all. Players have no specific motivation to face all the challenges, and they do not obtain a clear outcome when finishing each of them. Therefore, the relationship between actions and outcomes in a game is neither discernable nor integrated into the larger context of the game. This results in an unstructured advergame that does not support players in achieving objectives or motivate them to complete the whole experience. The design of the game prevents it from becoming a meaningful experience for players, which may have consequences for the effectiveness of the advergame. The lack of structure of the game may result in confused players who spend enormous energies trying to make sense of the whole experience. Such players may not retain the information conveyed through the game.

\section{Utility}

The utility of the advergame is what allows players to carry out the tasks they have to complete in the way they want (Rogers et al., 2011, p. 21). Therefore, utility is related to players' freedom within the advergame. I have previously stated that constraining players' freedom is not a smart way to convey advertising messages within digital games because this can result in unappealing advergames in which players feel that their performance does not have consequences for the outcome of the game. Therefore, players' freedom is related to meaningful play and by extension, to advergames' efficiency. Furthermore, utility is also directly connected with diversity, which, as we have already seen, is a way to motivate players. 


\section{Satisfaction}

Satisfaction is the pleasure derived from playing the advergame or from some aspect of it (González Sánchez et al., 2012, p. 1037). According to Salen and Zimmerman, digital games can provide two different types of pleasure: autotelic and extrinsic pleasures. Autotelic or intrinsic pleasures are those that "are significant only within the artificial meanings that game creates" while extrinsic pleasures "affect player's life outside the game" (Salen \& Zimmerman, 2004, p. 36o). Given that advergames' goals are focused on affecting players' feelings, attitudes and/or behaviors toward a brand or a product beyond the game (Wright-Isak \& Faber, 1997, p. 4), autotelic and extrinsic pleasures can help advertisers to reinforce players' bond with the brand both inside and outside the game.

In its advergame 20 Lives, Nokia followed a strategy that combined autotelic pleasures with extrinsic pleasures. The brand tried to generate extrinsic pleasures by giving physical Nokia devices to the best players in each life, and special prizes for those who collected information from all lives and were able to solve the final challenge. These kinds of outcomes not only reinforced players' bond with the brand but also motivated them to approach the game and return to it in order to improve their outcome.

Satisfaction is also directly connected with the attractiveness of the game, i.e. the capacity of specific properties of the game to arouse interest among players. Moreover, satisfaction is related to the degree of fun experienced by the player. It follows that this is a subjective aspect of playability, very difficult to measure and that depends a lot on players' personal circumstances and preferences.

\section{Table 2. Variables for the analysis of the advertising strategy}

\begin{tabular}{lll}
\hline ADVERGAME'S OBJECTIVES & PRODUCT INTEGRATION & ADVERGAME'S TARGET \\
- Advertising Goals & - Benefits & - Demographic/ Psycho- \\
- Game Goals & - High/Low-involvement & graphic/Geographic \\
& - Utilitarian/Hedonic & Characteristics \\
& - Commercial/Pro-social & - Attitude toward the \\
& - Search/Experience/ & Game \\
& & - Attitude toward the \\
& & Advertising Message \\
\hline ADVERGAME'S VISIBILITY & ADVERGAME'S CREDIBILITY & ADVERGAME'S PLAYABILITY \\
- Where is Placed & - Perceived Truthfulness & 1. Motivation \\
- When is Placed & - Perceived Discrepancies & 2. Learnability \\
- Complementary actions & & 3. Memorability \\
& & 4. Efficiency \\
& & 5. Utility \\
& & 6. Satisfaction \\
\hline
\end{tabular}


Table 2 gathers the six factors discussed in this chapter and their constituent aspects that should be taken into consideration in the analysis of an advergame's advertising strategy. This table can be used as a guide for the analysis of the advertising strategy of an advergame.

\section{References}

Armstrong, S. J. (2010). Persuasive Advertising. New York: Palgrave MacMillan.

Billich, C. (2010). Tohato, One of the Greats of Engagement Marketing on Mobile. SMLXL. From Interruption to Engagement.

Chen, J., \& Ringel, M. (2001). Can Advergaming be the Future of Interactive Advertising? Retrieved March $8^{\text {th }} 2012$ from http://www.kpe.com/ourwork/pdf/ advergaming.pdf

CLM BBDO, \& Les 84 (2010). Scorpio [Online Game].

$\mathrm{CP}+\mathrm{B}$ and Templar Games (2018). Domino's Piece of the Pie Pursuit [Digital Game]. Fishlabs. (2009). Volkswagen Polo Challenge [Digital Game].

González Sánchez, J. L., Gutiérrez Vela, F. L., Montero Simarro, F., \& Padilla-Zea, N. (2012). Playability: analysing user experience in video games. Behaviour \& Information Technology, 31(10), 1033-1054.

Goodbye, Silverstain, \& Partners (2008). Hotel 626 [Digital Game].

Goodbye Silverstain \& Partners, \& North Kingdom (2010). Battle of Cheetos [Digital Games].

Heide, J., \& Nørholm Just, S. (2009). Playful persuasion. The Rhetorical Potential of Advergames. Nordicom Review, 30(2), 53-68.

Hello Design (2009). Hit it Pure [Digital Game].

Joannis, H. (1996). La creación publicitaria desde la estrategia de marketing. Bilbao: Deusto.

Juul, J. (2010). A Casual Revolution: Reinventing Video Games and their Players. Cambridge, MA: MIT Press.

Kempt, C. (2009). Advergames. Natural Selection in the Online Ecosystem. Contagious. Retrieved February $23^{\text {rd }} 2012$ from http://www.kempt.co.uk/articles/ Contagious_Sept_09_Advergames.pdf.

Kirby, J., \& Marsden, P. (2006). Connected Marketing. Oxford: Elsevier.

KMF, Artificialduck Studios, Electric Umbrella, \& FxLab (2009). Golf GTI Tracks [Digital Game].

KwelBox (2002) Flip the Mix [Digital Game].

MacKenzie, S. B., \& Lutz, R. J. (1989). An Empirical Examination of the Structural Antecedents of Attitude toward the Ad in an Advertising Pretesting Context. Journal of Marketing, 53(2), 48-65. 
Messaris, P. (1997). Visual Persuasion. London: SAGE Publications.

Netzbewegung GmbH (2009). Capri-Sonne Fun World [Online Game].

O'Keefe, D. J. (1990). Persuasion: Theroy and Research. Newbury Park, CA: Sage.

Plummer, J. T. (1971). A Theoretical View of Advertising Communication. The Journal of Communication, 21(December), 315-324.

Rogers, Y., Sharp, H., \& Preece, J. (2011). Interaction Design. Beyond Human-Computer Interaction. Chichester: John Wiley \& Sons.

Rollings, A., \& Adams, E. (2003). Andrew Rollings and Ernest Adams on Game Design. Indianapolis: New Riders.

ROSAPARK \& MerciMichel (2017). OUIGO - Let's Play [Digital Game].

Salen, K., \& Zimmerman, E. (2004). Rules of Play: Game Design Fundamentals. Cambridge, MA: MIT Press.

Soleil Noir \& Chez Eddy (2010). Nespresso Variations [Digital Game].

Spurgeon, C. (2008). Advertising and New Media. New York: Routledge.

Stiff, J., \& Mongeau, P. A. (2003). Persuasive Communication. New York: The Guilford Press.

Tribal DDB (2009). Volkswagen: The New Golf [Digital Game].

Valentin \& Byhr, Normal Inc., \& Lucky Punk (2010). Volvo FMX [Digital Game]. Wright-Isak, C., \& Faber, R. J. (1997). Comprehensive Measurement of Advertising Effectiveness: Notes From the Marketplace. Paper presented at the Advertising and Consumer Psychology Conference, New Jersey.

Zupa, Capsize, \& hello monday (2010). Free your dance [Digital Games]. 